\title{
Mínimo e máximo em estruturas nominais - uma análise semântica ${ }^{1}$
}

\author{
Rui Marques \\ Universidade de Lisboa, CLUL
}

\begin{abstract}
:
This paper is concerned with the semantics of the portuguese phrases with the form o mínimo/máximo $\mathrm{N}$ ('the minimum N') and o mínimo/máximo de $\mathrm{N}$ ('the minimum/maximum of N'). Some nouns may occur in both of these constructions, while others might occur in only one of them, and still other nouns might occur only if accompanied by a modal operator. The proposal is made that these facts can be straightforwardly explained by the hypothesis that the first and the second of these syntactic constructions have, respectively, an extensional and an intensional meaning, together with the fact that some nouns have the same denotation in any possible world, while others denote different sets of entities in different possible worlds.
\end{abstract}

Keywords: minimizers/maximizers, possible worlds, nominal quantification, extensionality, intensionality

Palavras-chave: minimizadores/maximizadores, mundos possíveis, quantificação nominal, extensionalidade, intencionalidade

\section{Introdução}

Existe um vasto corpo de literatura sobre expressões comummente designadas por "minimizadores", como é o caso de um tostão furado ou mexer uma palha, entre muitos outros exemplos. As principais questões que têm sido levantadas a respeito destas expressões prendem-se com a sua distribuição, os valores semânticos a que são sensíveis e o seu valor retórico (ver, e.g., Horn (1972), Fauconnier (1975), Giannakidou (1997), Hoeksema (2000), Israel (2001)). Um outro termo frequentemente usado para designar estas expressões é o termo "Itens de polaridade negativa" (IPN), dada a possibilidade de ocorrerem em frases negativas por contraste com a impossibilidade ou restrição fortemente condicionada de ocorrerem em frases afirmativas. No entanto, como é reconhecido, pelo menos algumas destas expressões podem ocorrer nalgumas frases não negativas, como mostra o exemplo foi atingido na cabeça antes de ter visto vivalma (ver, e.g., Peres (2013) para outros exemplos e uma descrição de itens de polaridade negativa, e itens de polaridade positiva, em português), pelo que o termo IPN se pode tornar enganador. Além de minimizadores, há também "maximizadores", como todo o dinheiro do mundo.

Os minimizadores e os maximizadores identificam valores extremos de uma escala, o limite inferior, no caso dos minimizadores, e o limite superior, no caso dos maximizadores. Para além de expressões fixas como um tostão furado, um chavo, pregar olho, entre muitas outras, há outras formas do português de identificação do valor limite de uma escala. É esse o caso, por exemplo, de sintagmas como o limite inferior/superior, de sintagmas superlativos, como o dia mais quente do ano, e também de sintagmas nominais com os operadores máximo ou mínimo, como a capacidade máxima ou o mínimo entusiasmo, de que se ocupa o presente texto.

Os operadores máximo e mínimo podem ocorrer em Sintagmas Nominais definidos e indefinidos, em posição pós-nominal ou pré-nominal:

(1) a. É preciso fixar um limite máximo (de páginas para um artigo da revista).

b. Tem de haver um mínimo de consideração!

\footnotetext{
${ }^{1}$ Financiado com verbas do projeto estratégico do Centro de Linguística da Universidade de Lisboa UID/LIN/00214/2019.
} 
(2) a. Qual é a idade máxima (para se poder ter desconto no bilhete)?

b. Os sindicatos reivindicam um aumento do salário mínimo nacional.

c. 18 anos é a idade mínima para se poder votar.

d. Qualquer pessoa quer vender pelo preço máximo que conseguir.

(3) a. O edifício já não oferece a mínima segurança!

b. Tentamos oferecer o máximo conforto aos nossos hóspedes!

Os Sintagmas com o operador mínimo/máximo em posição pós-nominal identificam um valor determinado e nas construções com o operador em posição pré-nominal um valor indeterminado. Vejam-se os seguintes exemplos:

(4) a. É preciso que um médico dedique o tempo mínimo a atender cada doente.

b. É preciso que um médico dedique o mínimo (de) tempo a atender cada doente.

(5) a. Em cada espetáculo tentamos atingir a lotação máxima.

b. Em cada espetáculo tentamos atingir $\{$ a máxima lotação / o máximo de lotação $\}$.

Em (4a) o sintagma o tempo mínimo refere uma certa quantidade de tempo, concreta e convencionalmente aceite. Por contraste, em (4b) o sintagma o mínimo (de) tempo não se refere a uma quantidade de tempo específica, podendo tratar-se de quantidades de tempo diferentes para cada doente. Analogamente, em (5a) o sintagma a lotação máxima identifica um valor constante, o número de lugares da sala de espectáculos em causa, enquanto em (5b) o sintagma com o operador máximo identifica um valor que pode variar de espetáculo para espetáculo.

Nos sintagmas com o operador mínimo/máximo em posição pré-nominal, este operador pode aplicarse diretamente à estrutura nominal (o nome com os seus argumentos e modificadores nominais, se os houver; doravante $N$ ), como em a mínima ideia ou o máximo respeito pelos clientes, ou indiretamente, por intermédio da preposição de, como em o mínimo de condições ou o máximo de consideração. Como se verá, há restrições aos nomes que podem entrar numa e noutra destas construções (a de aplicação direta e a de aplicação indireta do operador mínimo/máximo à estrutura nominal). Partindo desta observação, colocam-se as seguintes questões, que norteiam este texto:

- Quais os nomes que podem entrar na construção de aplicação direta do operador mínimo/máximo à estrutura nominal e quais os que podem entrar na construção de aplicação indireta?

- Essas restrições à distribuição dos nomes pelas duas construções devem-se a razões semânticas?

\section{Classes de nomes e aplicação direta ou indireta do operador}

Considerando as duas construções sintáticas acima identificadas, a de aplicação direta do operador mínimo/máximo à estrutura nominal e a de aplicação indireta, com a preposição de, verifica-se que há nomes que podem entrar numa destas construções mas não na outra, nomes que podem entrar em ambas as construções e nomes que, sem a presença de modificadores nominais modais, não podem entrar em nenhuma das construções. É o que mostram os dados abaixo: 
(i) Nomes como ideia, dúvida, certeza, suspeita ou efeito podem ocorrer na construção de aplicação direta (o mínimo/máximo $\mathrm{N}$ ), mas não na de aplicação indireta (o mínimo/máximo de $\mathrm{N}$ ). Vejam-se os seguintes exemplos, em que a substituição de a mínima ideia/dúvida por o mínimo de ideia/dúvida geraria agramaticalidade:

(6) a. "Quando realizo um borrão, quando dobro a folha, ou a tela, não tenho a mínima ideia de qual vai ser o resultado final." (CETEMPÚBLICO, par=ext1483576-clt-93b-2)

b. "Não há a mínima dúvida que, ao longo da próxima temporada, a melhor equipa técnica de motores será muito solicitada." (CETEMPÚBLICO, par=ext85268-des-96b-2)

c. "Mestre do audiovisual, o cabelo cinzento a acentuar o bom aspecto, o mais pequeno gesto perfeitamente articulado para obter o máximo efeito, o chefe do Likud trucidou verdadeiramente o primeiro-ministro." (CETEMPÚBLICO, par=ext1172191-nd-96a-2)

(ii) Nomes como poluição, fumo, fruta, água e restantes nomes massivos, tal como nomes contáveis pluralizados, têm o comportamento inverso: podem entrar na construção de aplicação indireta (o mínimo/máximo de $\mathrm{N}$ ), mas não na de aplicação direta ( o mínimo/máximo $\mathrm{N}$ ):

(7) a. "O governo autorizou finalmente os organismos de assistência a procurar o mínimo de água e víveres, mas as condições sanitárias deploráveis fazem recear epidemias de desinteria e cólera.” (CETEMPÚBLICO, par=ext1456189-pol-95a-2)

b. "Quando chegou ao mercado, a «Exame Informática» era um 'franchising' de um título do grupo brasileiro Abril, a «Informática Revista», concebida para aproveitar o máximo de material com o mínimo de pessoas". (CETEMPÚBLICO, par=ext277130-clt-98a-1)

Quer em (7a) quer em (7b) a omissão da preposição de nos sintagmas sublinhados geraria agramaticalidade, mesmo com as alterações morfológicas do artigo e de mínimo/máximo para as formas femininas nos casos em que o nome é feminino.

(iii) Nomes como trabalho, coerência, credibilidade, barulho, entre muitos outros, podem ocorrer em ambas as construções. Vejam-se os seguintes exemplos, em que a substituição da forma $o$ mínimo $\mathrm{N}$ por $o$ mínimo de $\mathrm{N}$ ou vice-versa mantém a gramaticalidade e não altera o significado:

(8) a. "Este pormenor não agrada a nenhum agricultor, porque o jurista «ganha umas coroas sem ter $\underline{0}$ mínimo de trabalho»". (CETEMPÚBLICO, par=ext211854-soc-93b-1)

b. “«Vamos ter o máximo de cuidado», afirma um responsável do Inatel, Albino Maria.” (CETEMPÚBLICO, par=ext10737-soc-98a-2)

c. "O problema é que a maior parte dos seus compatriotas não está a manifestar o mínimo interesse pela elaboração de cadernos eleitorais.” (CETEMPÚBLICO, par=ext1382752-pol-95a-1)

d. "Os Genesis merecem o máximo respeito e consideração."

(CETEMPÚBLICO, par=ext1264626-clt-92b-1) 
(iv) Nomes como altura, peso, tempo ou distância não podem ocorrer em nenhuma das construções, a menos que sejam acompanhados por um modificador modal, como o adjetivo possível ou uma relativa como que conseguirmos. Veja-se que nos exemplos que se seguem a omissão do adjetivo possível tornaria as estruturas agramaticais:

(9) a. “Um dos pontos fortes do Freelance é a ajuda inteligente à preparação do material de apoio a uma conferência, por forma a que os utilizadores tenham que perder o mínimo tempo possível com questões de «design» e impressão." (CETEMPÚBLICO, par=ext686888-clt-soc-93a-1)

b. "Os testes que se fizeram foram o do yoyo, no qual os atletas percorrem o máximo de distância possível em sprints intervalados por cinco segundos (...)"

(CETEMPÚBLICO, par=ext47996-des-98a-1)

A tabela que se segue resume estas observações:

\begin{tabular}{|c|c|c|c|}
\cline { 3 - 4 } \multicolumn{2}{c|}{} & mínimo/máximo $\mathrm{N}$ & mínimo/máximo de $\mathrm{N}$ \\
\hline (i) & ideia, dúvida,$\ldots$ & ok & $*$ \\
\hline (ii) & água, poluição, livros,$\ldots$ & $*$ & Ok \\
\hline (iii) & brilho, respeito, conforto, $\ldots$ & ok & Ok \\
\hline (iv) & altura, peso, tempo, distância,$\ldots$ & $*$ & $*$ \\
\hline
\end{tabular}

Tabela 1 - construções de aplicação (in)direta do operador e classes de nomes

Perante estes dados, comecemos por questionar por que razão é que com os nomes da classe (iv) parece ser obrigatória a presença de um operador modal e com os das outras classes não.

\section{Nomes escalares e obrigatoriedade da presença de modificador modal}

Os nomes da classe (iv), com os quais a ausência de um modificador modal, como possível, gera agramaticalidade nas construções consideradas, são nomes que identificam uma escala, um conjunto de pontos ordenados de acordo com uma dimensão. Mais concretamente, cada um destes nomes identifica uma escala aberta, ou seja, uma escala sem limites intrínsecos. Para se considerar uma escala de, e.g., peso fechada (com limites superior e inferior), será necessário recorrer a adjuntos, como entre 80 e 90 quilos ou até $70 \mathrm{~kg}$, ou a outros meios linguísticos cujo significado leve a considerar apenas um segmento da escala relevante. Para clarificação, considerem-se os seguintes exemplos:

(10) a. Alguma vez alguém se terá dado ao trabalho de calcular o peso de todas as entidades que compõem o universo?

b. Participam nesta classe os atletas com peso até $90 \mathrm{Kg}$.

c. Pagam uma taxa adicional todas as encomendas com peso igual ou superior a $600 \mathrm{~g}$.

d. Perdi menos peso do que era suposto quando comecei a dieta.

O significado de qualquer destas construções envolve a consideração da escala do peso, identificada pelo nome peso, mas enquanto em (10a) é relevante considerar esta escala na sua totalidade, nos outros casos o que é relevante considerar é apenas um segmento da mesma: em (10b), um conjunto ordenado de graus até um limite superior $(90 \mathrm{~kg})$; em (10c) um conjunto ordenado de graus com um limite inferior; e em (10d) um con- 
junto de dois graus, o que corresponde ao peso que o enunciador perdeu na altura relevante e o que corresponde ao peso que era suposto perder. Em qualquer das construções, a palavra peso identifica a escala do peso, uma escala aberta, sendo outros constituintes (e.g. o adjunto até $90 \mathrm{~kg}$ ) que contribuem para a consideração de um conjunto de pontos fechado, um segmento da escala.

Assim, é possível perceber a razão para a impossibilidade da construção o mínimo/máximo (de) N quando $\mathrm{N}$ é um nome escalar, como peso, altura ou velocidade: por um lado, a denotação de nomes como peso, altura, tempo, área, volume, etc. corresponde a uma escala aberta (i.e., sem limites intrínsecos); por outro lado, os Sintagmas Nominais definidos, como é o caso de sintagmas com a forma o mínimo/máximo (de) $\mathrm{N}$, estão associados a pressuposição existencial. Ou seja, um sintagma como o mínimo (de) peso tem a pressuposição de que existe um valor mínimo de peso, tal como um sintagma como o máximo de tempo tem a pressuposição de que existe um valor máximo de tempo. No entanto, como estes nomes denotam uma escala aberta, sem limites inferior ou superior, a pressuposição não pode ser satisfeita. Por outras palavras, há uma contradição entre a pressuposição existencial desencadeada pelo Sintagma Nominal definido o mínimo/máximo $($ de $) \mathrm{N}$ e o facto de o $\mathrm{N}$ denotar uma escala sem um limite mínimo ou máximo.

Esta contradição pode ser resolvida de duas formas: eliminando a pressuposição existencial ou impondo limites à escala considerada. Para a primeira opção (eliminação da pressuposição existencial), bastará substituir o artigo definido por um artigo indefinido, já que os Sintagmas Indefinidos não desencadeiam a pressuposição existencial. A boa formação de (11a), por oposição à ausência de sentido de (11b), confirma que é a contradição acima referida que explica a estranheza de o mínimo/máximo (de) $\mathrm{N}$ com nomes escalares:

(11) a. Eles só querem percorrer um mínimo de distância!

b. ??Eles só querem percorrer o mínimo de distância!

A outra opção de resolver a dita contradição consiste em impor limites à escala denotada pelo nome (se for considerada uma escala com limite inferior, a pressuposição existencial desencadeada pelo sintagma $o$ mínimo (de) $\mathrm{N}$ estará satisfeita, do mesmo modo que a pressuposição desencadeada pelo sintagma o máximo (de) $\mathrm{N}$ ficará satisfeita se for considerada uma escala com limite superior). É o que se verifica com a adição de modificadores modais, como nos seguintes exemplos:

(12) a. O prédio ultrapassa o máximo de altura permitida por lei.

b. Ele quer demorar o mínimo (de) tempo possível.

c. Tenta carregar o camião com o máximo (de) peso que conseguires.

Sem o constituinte em itálico, estas construções seriam pelo menos muito estranhas, pela razão observada acima (impossibilidade de satisfação da pressuposição existencial induzida associada ao Sintagma Nominal definido pelo facto de o nome denotar uma escala aberta). O modificador nominal, em itálico, impõe limites ao conjunto de pontos que formam a escala denotada pelo nome a que se aplicam: em (12a), o constituinte altura permitida por lei não denota todos os graus de altura, mas apenas os que são cobertos pela legislação em vigor; em (12b), tempo possível denota um conjunto finito de quantidades de tempo e não todas as quantidades de tempo, tal como em (12c) peso que conseguires denota um conjunto finito de graus. Assim, a pressuposição existencial associada ao Sintagma Nominal definido fica satisfeita.

Posto isto, passemos agora à consideração das outras classes de nomes identificadas na Tabela 1, acima. 


\section{As classes de nomes (i)-(iii)}

Como observado acima, nomes como dúvida, ideia ou inconveniente, entre vários outros, podem ocorrer na construção de aplicação direta do operador mínimo/máximo (a construção o mínimo/máximo $\mathrm{N}$ ), mas não na construção de aplicação indireta do operador (a construção o mínimo/máximo de $\mathrm{N}$ ), enquanto outros nomes, como os massivos ou nomes contáveis pluralizados, têm o comportamento inverso:

(13) a. Não vejo o mínimo inconveniente. / ??Não vejo o mínimo de inconveniente.

b. Não há a mínima dúvida! / ??Não há o mínimo de dúvida!

(14) a. ??Ele não consome o mínimo álcool! / Ele não consome o mínimo de álcool!

b. ??Quero ler o máximo livros possível. / Quero ler o máximo de livros possível.

À primeira vista, este contraste não tem nada de particular digno de registo: o sintagma $o$ mínimo $\mathrm{N}$ tem valor referencial, identificando uma entidade "simples" (e.g. uma dúvida, no caso do sintagma a mínima dúvida, equivalente a a mais pequena dúvida), enquanto o sintagma o mínimo/máximo de $\mathrm{N}$ é uma estrutura partitiva, identificando uma porção de uma entidade (e.g. uma porção de água em o mínimo de água). Por outras palavras, o sintagma o/a mínimo/a $\mathrm{N}$ identifica a entidade denotada por $\mathrm{N}$ mais pequena do que as outras entidades denotadas por $\mathrm{N}$, enquanto o sintagma o mínimo de $\mathrm{N}$ identifica uma porção da entidade denotada por N. Assim, a impossibilidade de nomes massivos ocorrerem na primeira estrutura será paralela à impossibilidade de, e.g., \#o líquido grande/pequeno (por contraste com o frasco grande/pequeno, por exemplo), e a impossibilidade de, e.g., \#o mínimo de dúvida será paralela à de, por exemplo, \#10\% de dúvida (por contraste com $10 \%$ de água, por exemplo).

O facto de nomes contáveis pluralizados terem o mesmo comportamento que os nomes massivos, uns e outros podendo ocorrer na construção de aplicação indireta do operador ( $o$ mínimo/máximo de $\mathrm{N}$ ) e não na de aplicação direta (o mínimo/máximo $\mathrm{N}$ ), será natural, dado que tanto os plurais como os massivos denotam estruturas reticulares (cf. Link 1983, ter Meulen 1980, e.o.). O sintagma o mínimo de N identificará uma parte da estrutura reticular cujo número de átomos é inferior ao de todas as outras partes da estrutura, pelo que a denotação de $\mathrm{N}$ terá de ser uma estrutura reticular. Por outras palavras, um sintagma como o mínimo de água será equivalente a a menor porção de água e o máximo de livros possível será equivalente a a maior soma de livros possível.

No entanto, a mera observação de que o sintagma com a forma o mínimo/máximo de $\mathrm{N}$ é uma estrutura partitiva e o sintagma com a forma o mínimo/máximo $\mathrm{N}$ não o é, como descrito nos parágrafos anteriores, não explica todos os dados.

A explicitação acima de que o sintagma com a forma o mínimo/máximo de $\mathrm{N}$ é uma estrutura partitiva, ao contrário de um sintagma com a forma o mínimo/máximo de $\mathrm{N}$, resulta na observação de que um sintagma com esta forma é parafraseável por a mais pequena / maior porção de $\mathrm{N}$, enquanto um sintagma com a forma o mínimo / máximo $\mathrm{N}$ é parafraseável por o mais pequeno / maior N. Se esta ideia pode explicar dados como os de (13) e (14), não parece sustentável quando se consideram outros exemplos das mesmas construções.

Em primeiro lugar, além de nomes massivos e de nomes contáveis pluralizados, há outros nomes que podem ocorrer na construção o mínimo/máximo de $\mathrm{N}$, mas não na construção de aplicação direta do operador (o mínimo/máximo N). É esse o caso de nomes como poluição, nevoeiro ou fumo, que se pode questionar se são nomes massivos. Uma vez que, no que respeita às construções em análise, estes nomes têm o mesmo comportamento que os massivos, como mostra (15), a observação de que a construção o mínimo / máximo de $\mathrm{N}$ é uma estrutura partitiva é no mínimo pouco informativa:

(15) a. Não mostres o mínimo de medo! 


\section{b. ??Não mostres o mínimo medo!}

Se é aceitável dizer que, e.g., o mínimo de água é parafraseável por a mínima porção de água, não parece fazer muito sentido que o mínimo de medo seja parafraseável por a mínima porção de medo.

Em segundo lugar, há um conjunto muito significativo de nomes que podem entrar quer na estrutura de aplicação direta do operador quer na de aplicação indireta e para os quais não faz sentido a afirmação de que $o$ mínimo/máximo $\mathrm{N}$ é parafraseável por o menor/maior $\mathrm{N}$ e o mínimo/máximo de $\mathrm{N}$ por a mínima/máxima porção de $\mathrm{N}$. É esse o caso de, entre muitos outros, nomes como os indicados em (16), a que se seguem exemplos ilustrativos:

(16) interesse, credibilidade, uniformidade, sentido crítico, conhecimento, dignidade, qualidade, condições, sensibilidade, exigência, privacidade, meios, custos, recursos, justiça, razoabilidade, segurança, pudor, garantias, força, cuidado, graça, prejuízo, competência, turbulência, ruído, consistência, consideração, barulho, desperdício, trabalho, compromissos, mobiliário, inconvenientes, vocação, coerência, seriedade, risco, ambição, fidelidade, publicidade, optimismo, esforço, conforto, coordenação, consenso, preparação, autonomia, gozo, idoneidade, dano,...

(17) a. O objetivo de um ataque militar é causar o máximo dano possível ao inimigo.

b. O objetivo de um ataque militar é causar o máximo de dano possível ao inimigo.

(18) a. Ele não tem o mínimo cuidado com o carro!

b. Ele não tem o mínimo de cuidado com o carro!

Em terceiro lugar, a observação em causa não explica os seguintes contrastes:

(19) a. Já não há o mínimo vestígio da passagem do furacão.

b. '?Já não há o mínimo de vestígios da passagem do furacão.

c. $\quad{ }^{0 \mathrm{k} / ?} \mathrm{Nas}$ escavações arqueológicas nesta região, nunca se encontrou o mínimo de vestígios ro-

$\underline{\operatorname{manos}}$.

(20) a. Ninguém teve o mínimo bom senso de abrir a janela?

b. *Ninguém teve o mínimo de bom senso de abrir a janela?

c. Ninguém $\{$ ' teve/tinha/tem $\}$ o mínimo de bom senso?

O contraste entre (19a) e (19b), tal como o contraste entre (20a) e (20b), mostra que os nomes vestígio e bom senso podem ocorrer na estrutura de aplicação direta do operador mínimo/máximo à estrutura nominal, mas não na estrutura de aplicação indireta. No entanto, os exemplos (19c) e (20c) são claramente mais aceitáveis do que (19b) e (20b), apesar de também terem a estrutura o mínimo de N. Assim, o contraste entre as alíneas (b) e (c) mostra que a estranheza das primeiras não se deve apenas ao tipo de nome a que se aplica o operador mínimo/máximo. Além disso, para os exemplos em (20a) e (20c) o comentário acima a propósito de (15) e de nomes como medo é igualmente válido.

Os dados apresentados em (19) e (20) sugerem que na referência a situações particulares, episódicas, a construção o mínimo $\mathrm{N}$ é mais natural que a construção o mínimo de N. Veja-se que em (19a) e (19b) é feita referência à passagem de a um furacão particular (i.e., a uma situação episódica), ao contrário do que se verifica em (19c), em que se faz referência a escavações arqueológicas, que podem ter sido várias, ao longo do tempo. Também em (20a) e (20b) é feita referência a uma situação particular, perguntando-se se nessa situa- 
ção concreta ninguém abriu a janela. Já em (20c), a pergunta não incide sobre uma situação específica, mas sobre uma caraterística de cada indivíduo e a aceitabilidade da construção $o$ mínimo de $\mathrm{N}$ melhora. $\mathrm{O}$ exemplo (20c) permite, além disso, observar que com tempos verbais que favorecem uma leitura episódica, como o Pretérito Perfeito do Indicativo, a aceitabilidade da estrutura o mínimo de $\mathrm{N}$ é pior do que se forem usados outros tempos verbais, como o Pretérito Imperfeito do Indicativo ou o Presente do Indicativo. Em suma, os dados (19) e (29) sugerem uma relação entre a inaceitabilidade da estrutura o mínimo de $\mathrm{N}$ e a consideração de situações episódicas.

Partindo desta pista, formulo a seguinte hipótese:

HIPÓTESE: Na estrutura $o$ mínimo/máximo N, N tem interpretação extensional; na estrutura $o$ mínimo/máximo de N, N tem interpretação intensional.

Por outras palavras, na primeira estrutura a denotação de $\mathrm{N}$ diz respeito apenas ao mundo de avaliação (por defeito, o mundo real), enquanto na segunda estrutura a denotação de $\mathrm{N}$ diz respeito a vários mundos possíveis.

Simplificadamente, a ideia na base desta hipótese é que, em exemplos como (19a-b) ou (20a-b), se considera a denotação do nome vestígios e bom senso tendo em conta apenas a situação particular que é referida na frase, enquanto em (19c) e em (20c) se considera a denotação desses nomes em qualquer situação.

\section{Denotação de nomes e mundos possíveis}

A hipótese de que na estrutura o mínimo/máximo de $\mathrm{N}$ o nome tem interpretação intensional pode parecer absurda, ou pelo menos estranha, se pensarmos em exemplos clássicos de leitura intensional de estruturas nominais, como a dos sintagmas sublinhados nos seguintes exemplos:

(21) a. O que ele queria era um carro movido a água!

b. Precisávamos de uma secretária que falasse dez línguas.

c. Ele acredita que há um fantasma na torre do castelo.

Os sintagmas sublinhados nestes exemplos referem entidades virtuais, que não existem, ou podem não existir, na realidade, mas apenas noutros mundos possíveis. Pelo contrário, nas frases abaixo, as estruturas nominais sublinhadas fazem referência a entidades reais:

(22) a. Basta haver o mínimo de água no tubo para haver alteração nos resultados.

b. As barreiras de proteção foram inúteis, não evitaram o mínimo de danos provocados pelo tsunami.

No entanto, é preciso ter em conta que os constituintes nominais sublinhados nos exemplos (21) e os dos exemplos (22) são de natureza sintática diferente (os primeiros são Sintagmas Nominais e os segundos, um nome e um nome modificado, não o são) e desempenham diferentes funções semânticas. Os Sintagmas Nominais em (21) têm função referencial, identificam entidades, enquanto os nomes (com ou sem complementos e modificadores) não identificam entidades, mas têm sim uma função de classificação do universo (ver, e.g., Peres (2013)). Por outras palavras, um sintagma como a mesa identifica um determinado objecto, mas o nome mesa não tem função referencial. Ao contrário do Sintagma Nominal, o nome não permite individualizar uma determinada entidade, permite sim classificar entidades como sendo mesas ou não. Ou seja, o nome mesa 
refere um conjunto de entidades do universo, as que são classificáveis como mesas, o que é o mesmo que dizer que a denotação do nome mesa é um conjunto de mesas.

Feita esta clarificação, veja-se agora que, além de Sintagmas Nominais, como nos exemplos (21), também os nomes (com ou sem complementos ou modificadores) podem ter leitura intensional. Isso é evidente no caso de nomes que classificam entidades virtuais, como os nomes gnomo ou fantasma, mas a consideração de mundos possíveis alternativos também se pode colocar para outros nomes. Tome-se como exemplo os nomes obstáculo e rio. É possível um rio ser um obstáculo à realização de um percurso entre dois pontos, pelo que esse rio fará parte da denotação do nome obstáculo. Isto é, o nome obstáculo (à realização de um percurso entre $\mathrm{A} e \mathrm{~B}$ ) denota o conjunto dos obstáculos à realização do percurso entre $\mathrm{A} \mathrm{e} \mathrm{B}$, conjunto este que é composto por todas as entidades classificáveis como obstáculos, pelo que o rio em causa fará parte da denotação no nome obstáculo. No entanto, esse mesmo rio não será obstáculo à realização do percurso se, por exemplo, tivermos um barco que nos permita atravessar o rio, ou se existir uma ponte. Assim, nalguns mundos possíveis o rio em causa faz parte da denotação do nome obstáculo, mas noutros mundos (e.g., em mundos em que há uma ponte) não o faz. Mas em qualquer dos mundos possíveis em que existe, o rio em causa faz parte da denotação do nome rio. Por outras palavras, um rio pode ser um obstáculo à realização de um percurso ou não o ser, mas será sempre um rio. Significa isto que a denotação do nome obstáculo é mais variável de mundo possível para mundo possível do que a do nome rio. Ou seja, o rio em causa faz parte da denotação do nome obstáculo nalguns mundos possíveis, mas não noutros, e faz parte da denotação do nome rio em qualquer dos mundos em que existe.

Generalizando, para qualquer entidade $x$ e nome $N$, pode colocar-se a seguinte questão:

(23) Se uma entidade $x$ pode ser classificada como $\mathrm{N}$ num mundo possível $w, x$ pode ser classificada pelo mesmo nome nos mundos possíveis alternativos a $w$ ?

Como visto, a resposta à questão (23) é negativa para alguns nomes, como obstáculo (o que é um obstáculo num mundo possível pode não o ser noutro mundo possível), e afirmativa para outros, como rio (se uma entidade é um rio num mundo possível é rio em qualquer outro mundo possível em que exista).

Outros exemplos de nomes que, no que respeita a esta questão, são do mesmo tipo que obstáculo são nomes que classificam atitudes proposicionais, como dúvida, suspeita, desejo, esperança, etc. É possível que entre um indivíduo e uma proposição exista uma relação de dúvida e noutra situação a relação entre o mesmo indivíduo e a mesma proposição seja não de dúvida, mas de suspeita, de crença, de certeza, etc. Por outras palavras, é possível que aquilo que numa dada situação é uma dúvida se venha a tornar, por exemplo, uma certeza, ou que aquilo que numa dada situação é uma esperança noutro mundo seja uma impossibilidade, etc.

Assim, a respeito destes nomes, não se pode dizer que a sua referência seja constante de mundo possível para mundo possível. Antes pelo contrário; se uma entidade que é classificável por $N$ num dado mundo possível pode não o ser noutro mundo possível, então a referência de $N$ não será a mesma em qualquer mundo possível. Por outras palavras, a denotação de um nome como osbtáculo será um conjunto de entidades num mundo possível que pode ser diferente do conjunto que esse nome denota noutro mundo possível (num mundo possível uma determinada pedra pode ser um obstáculo à realização de um evento e noutro mundo não o ser, mas sê-lo, por exemplo, o tempo disponível, o vento, etc.). Analogamente, a denotação do nome dúvida será em cada mundo possível uma relação entre indivíduos e proposições, mas os indivíduos e as proposições que fazem parte desta relação não são os mesmos em todos os mundos possíveis.

Também a respeito de nomes como estudante, médico, diretor, presidente, etc. se pode dizer que a resposta à questão enunciada em (23) é negativa, tal como se pode dizer que a referência destes nomes não é a mesma em todos os mundos possíveis. De facto, se num dado mundo possível uma pessoa é, e.g., diretor, isso não implica que seja diretor em qualquer outro mundo possível. Por exemplo, suponhamos que um dado dire- 
tor ganhou as eleições e, consequentemente, assumiu o cargo de diretor. É fácil observar que em mundos possíveis alternativos, em que não ganhou as eleições ou, por qualquer outra razão, não tomou posse como diretor, essa entidade não será classificável pelo nome diretor. Ou seja, o facto de uma entidade $x$ ser diretor num mundo possível não implica que o seja em qualquer outro mundo possível. De igual modo, é fácil observar que a referência do nome diretor não é a mesma em todos os mundos possíveis. Num mundo possível em que $x$ ganhou as eleições e tomou posse como diretor, $x$ faz parte da referência do nome diretor nesse mundo possível (i.e., pertence ao conjunto dos diretores que existem nesse mundo), mas não num mundo possível em que perdeu as eleições ou não chegou a tomar posse como diretor.

Em síntese, com todos estes nomes se verifica que a resposta à questão (23) é negativa. Se uma entidade é $N$, sendo $N$ um dos nomes como obstáculo, dúvida ou diretor, num mundo possível, isso não implica que seja $N$ em qualquer mundo possível alternativo. Consequentemente, a respeito destes nomes não se pode dizer que tenham a mesma denotação em todos os mundos possíveis.

Por contraste, a resposta à questão enunciada em (23) é afirmativa para nomes como rio, como visto acima, tal como o é para outros nomes que classificam entidades simples, como pedra, montanha ou árvore. Ou seja, se $x$ é uma montanha num mundo possível, será uma montanha em qualquer outro mundo possível.

No entanto, não se pode dizer que a referência destes nomes seja a mesma em qualquer mundo possível. De facto, a referência de qualquer destes nomes é um conjunto de indivíduos (o conjunto dos rios, no caso do nome rio, o conjunto das pedras, no caso do nome pedra, etc.) e o conjunto de, e.g., montanhas que existe num mundo possível não é necessariamente o mesmo que existe noutro mundo possível, tal como o conjunto das pedras que existem atualmente não é necessariamente o mesmo que o das que existem em qualquer mundo possível, etc. Ou seja, o facto de uma entidade que é, e.g., montanha num dado possível ser montanha em qualquer outro mundo possível em que exista não implica que o conjunto das montanhas que existem em cada mundo possível seja o mesmo que o das montanhas que existem nos outros mundos possíveis.

Finalmente, considerem-se nomes como ruído, luz, prazer, dor ou bom senso. A respeito destes nomes, creio poder-se dizer não só que, se uma entidade é classificável por $N$ num mundo possível, é classificável por $N$ em qualquer outro mundo possível, como também que $N$ tem a mesma denotação em todos os mundos possíveis. Ou seja, se, e.g., uma dada sensação pode ser classificada como dor num mundo possível, será classificável como dor em qualquer outro mundo possível e o nome dor identifica a mesma sensação em qualquer mundo possível.

O mesmo se pode dizer a respeito de nomes massivos, que identificam substâncias. Se uma dada substância é classificável por um nome $N$ num dado mundo possível, é classificável pelo mesmo nome em qualquer outro mundo possível. Por exemplo, se um determinado líquido é água, será água em qualquer mundo possível; se é azeite, será azeite em qualquer outro mundo possível, etc. Além disso, cada nome massivo identifica a mesma substância em qualquer mundo possível. Assim, tal como se verifica com nomes como dor, ruído ou bom senso, no que respeita aos nomes massivos há uma relação biunívoca entre o nome e a sua denotação em qualquer mundo possível: se uma entidade é classificável por $N$ num mundo possível, é classificável por $N$ em qualquer outro mundo possível, e a referência de $N$ é a mesma em qualquer mundo possível (o nome água identifica a mesma substância em qualquer mundo possível, tal como o nome dor identifica a mesma sensação em qualquer mundo possível, etc.).

Em síntese, no que respeita à questão enunciada em (23), observa-se que há um conjunto de nomes a respeito dos quais a resposta é afirmativa e um outro conjunto de nomes a respeito dos quais a resposta é negativa. Pertencem ao primeiro conjunto os nomes massivos, nomes como dor, ruído ou bom senso, e também nomes como rio, montanha ou pedra, sendo a resposta à questão (23) negativa para nomes como obstáculo e também para nomes como diretor, estudante, médico, etc., bem como para nomes como dúvida ou suspeita, que identificam atitudes proposicionais.

Uma outra questão, relacionada com a que é enunciada em (23), é a seguinte: 
(24) A referência de um nome num dado mundo possível é a mesma que a sua referência nos outros mundos possíveis?

Como visto, a resposta a esta questão é afirmativa no caso dos nomes massivos e de nomes como dor, ruído, bom senso, etc., e negativa no caso dos outros nomes que foram tidos em conta na resposta a (23). No caso de nomes como obstáculo, dúvida ou suspeita, bem como no caso de nomes como estudante, médico, ou diretor, a evidência de que a resposta a (24) também é negativa é imediata: se o facto de uma entidade ser classificável por $\mathrm{N}$ num mundo possível não implica que o seja noutros mundos possíveis, a referência de $\mathrm{N}$ em cada mundo possível não é a mesma que em qualquer outro mundo (se uma entidade $x$ é, e.g., um obstáculo num mundo possível e não o é noutro mundo possível, a referência do nome obstáculo num mundo possível inclui $x$, mas a sua referência noutros mundos não inclui). A respeito de nomes como árvore, montanha, ou rio, a resposta a (23) é afirmativa (i.e., se uma entidade é, e.g., árvore num mundo possível, é montanha em qualquer outro mundo possível), mas a resposta a (24) é negativa: é possível que, e.g., uma dada árvore exista num mundo possível e não exista noutro mundo, o que significa que o conjunto denotado pelo nome árvore não é o mesmo em todos os mundos possíveis (i.e., o conjunto de árvores que existe em cada mundo possível pode ser diferente do que existe noutros mundos). Finalmente, a respeito dos nomes massivos e de um vasto conjunto de nomes, como dor, prazer, bom senso, ruído, etc. a resposta a ambas as questões, enunciadas em (23) e em (24), é afirmativa. A respeito destes nomes, pode dizer-se que cada um deles identifica a mesma entidade em qualquer mundo possível (i.e., o nome água identifica a mesma substância em qualquer mundo possível, o nome dor identifica a mesma sensação em qualquer mundo possível, etc.) e se uma entidade é classificável por um desses nomes num mundo possível, é classificável pelo mesmo nome em qualquer outro mundo possível (se um dado líquido é água, será água em qualquer mundo possível, se um tipo de vibração do ar é ruído, será ruído em qualquer mundo possível, etc.).

A tabela abaixo sintetiza as observações feitas a respeito das questões enunciadas em (23) e em (24):

\begin{tabular}{|c|c|c|c|c|}
\cline { 2 - 5 } \multicolumn{1}{c|}{} & I & II & III & IV \\
\cline { 2 - 5 } \multicolumn{1}{c|}{} & obstáculo, dúvida, ... & médico, diretor, ... & rio, montanha, árvore, ... & dor, ruído, água, ... \\
\hline$(23)$ & Não & Não & Sim & Sim \\
\hline$(24)$ & Não & Não & Não & Sim \\
\hline
\end{tabular}

Tabela 2 - Classes de nomes e (in)constância de referência em diferentes mundos possíveis

Resumindo, a questão da relação entre nomes e entidades que referem vista numa perspetiva intensional, em que se tem em conta diferentes mundos possíveis, permite identificar três classes de nomes:

(i) Nomes que, se podem classificar uma entidade $x$, podem não classificar a mesma entidade em todos os mundos em que $x$ existe e não identificam as mesmas entidades em todos os mundos; exemplos: obstáculo, dúvida, ...

(ii) Nomes que, se podem classificar uma entidade $x$, podem classificar a mesma entidade em todos os mundos em que $x$ existe, mas a sua referência não é a mesma em todos os mundos; exemplos: pedra, montanha,...

(iii) Nomes que, se podem classificar uma entidade $x$, podem classificar a mesma entidade em todos os mundos em que $x$ existe (e.g., o tipo de vibração que é som num mundo possível também é 
som em qualquer outro mundo possível) e identificam a mesma entidade em todos os mundos possíveis (e.g., escuridão corresponde a ausência de luz em qualquer mundo possível); exemplos: ruído, luz, prazer, bom senso, dano, condições (de higiene), ...

\section{Classes de nomes e as construções o mínimo (de) $\mathbf{N}$}

Tendo sido definidas as classes de nomes apresentadas no final da secção anterior, retomemos agora a observação inicial que alguns nomes podem entrar na construção $o$ mínimo/máximo $\mathrm{N}$ e na construção $o$ mínimo/máximo de $\mathrm{N}$, enquanto outros nomes podem entrar numa mas não na outra construção.

Como mostram os exemplos abaixo, os nomes cuja referência não é a mesma em diferentes mundos possíveis (i.e., os nomes das classe I, II e III da tabela 2) podem entrar na construção o mínimo/máximo de $\mathrm{N}$ apenas na sua forma plural:

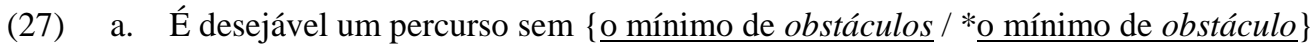

b. Ele quer turmas com \{o mínimo de estudantes $/ *_{0}$ mínimo de estudante $\}$

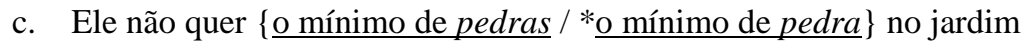

$\mathrm{Na}$ forma singular, os nomes das classes I e III podem entrar na construção o mínimo/máximo $\mathrm{N}$, mas não na construção o mínimo/máximo de $\mathrm{N}$, enquanto os nomes da classe II não parecem poder entrar em nenhuma das construções:

(28) a. Se ele encontrar o mínimo obstáculo no caminho, desiste imediatamente!

b. *Nem o mínimo estudante gostaria de assistir a uma aula dessas!

c. Ele não quer a mínima pedra no jardim!

A razão para os nomes da classe II terem um comportamento diferente dos das classes I e III deve-se provavelmente ao facto de o tamanho não ser uma dimensão relevante para a possibilidade de uma entidade ser classificável pelos nomes da classe II, ao contrário do que se verifica no que respeita aos nomes das classes I e III. Ou seja, o tamanho de uma entidade não é relevante para a questão de a mesma ser ou não ser classificável por nomes como estudante ou diretor, por exemplo, mas é relevante para a possibilidade de a mesma poder ou não ser classificável por nomes como obstáculo ou pedra, por exemplo. Por outras palavras, a denotação de nomes como obstáculo ou pedra é um conjunto de entidades que tenham um determinado tamanho mínimo, enquanto a denotação de nomes como estudante ou diretor é um conjunto de entidades cujo tamanho é irrelevante para a sua pertença ao conjunto. Assim, sintagmas como o mínimo diretor ou o mínimo estudante são absurdos por conterem um adjetivo - mínimo - que remete para uma propriedade (o tamanho) que não faz parte do significado do nome, ao contrário do que se verifica com sintagmas como o mínimo obstáculo ou a mínima pedra.

Em suma, no que respeita aos nomes que denotam conjuntos diferentes em diferentes mundos possíveis, verifica-se que podem ocorrer na construção o mínimo $\mathrm{N}$ na sua forma singular (excetuando os nomes da classe II, de cujo significado não faz parte a dimensão tamanho), mas na construção o mínimo de $\mathrm{N}$ só podem ocorrer na forma plural.

Além disso, com estes nomes, a interpretação das construções é diferente. Em (29a), a construção $o$ mínimo obstáculo é parafraseável por o obstáculo mais pequeno e em (29b) a por a mínima quantidade de $\mathrm{N}$. Vejam-se os seguintes exemplos:

(29) a. Se ele encontrar o mínimo obstáculo, desiste!

[o mínimo obstáculo $\equiv$ o obstáculo mais pequeno] 
b. Se ele encontrar o mínimo de obstáculos, desiste!

[o mínimo de obstáculos $\equiv$ a menor quantidade de obstáculos]

Por contraste, nomes da classe IV, que, como visto acima, identificam a mesma entidade em todos os mundos, podem ocorrer na forma singular quer na construção o mínimo $\mathrm{N}$ quer na construção $o$ mínimo de $\mathrm{N}$ sem diferença de significado:

(30) a. Não quero ouvir o mínimo ruído / o mínimo de ruído [झ]

b. O objetivo de um ataque militar é causar o máximo dano / o máximo de dano ao inimigo [झ]

Creio que a hipótese acima formulada de que na construção o mínimo $\mathrm{N}$, a estrutura nominal $N$ tem interpretação extensional e na construção o mínimo de $\mathrm{N}$ tem interpretação intensional permite explicar não só a diferente distribuição dos nomes pelas duas construções (simplificadamente, nomes que denotam conjuntos diferentes em diferentes mundos possíveis podem ocorrer na primeira construção na forma singular e na segunda construção apenas na forma plural, enquanto nomes que têm a mesma denotação em todos os mundos possíveis podem ocorrer em ambas as construções) como a (não) equivalência do significado das duas construções.

Como visto na secção anterior, os nomes ocorrem em itálico nos exemplos (30) têm a mesma denotação em qualquer mundo possível: em qualquer mundo possível ruído identifica a mesma entidade, uma vibração sonora com determinadas caraterísticas, como ser captável pelo ouvido humano, etc.; em qualquer mundo possível dano identifica uma alteração prejudicial, etc. Assim, quer se tenha em conta a denotação do nome num único mundo possível quer a sua denotação em todos os mundos possíveis, a denotação do nome é a mesma. Daí a equivalência de significado que se verifica nos exemplos de (30) entre as construções $o$ mínimo/máximo $\mathrm{N}$ e o mínimo/máximo de $\mathrm{N}$.

Já no que respeita a nomes como obstáculo ou dúvida, a situação é diferente. Como visto acima, estes nomes denotam conjuntos diferentes em diferentes mundos possíveis: o que é um obstáculo num mundo possível pode não o ser noutro mundo, tal como o que é uma dúvida num mundo possível pode não o ser noutro mundo, etc.; i.e., em diferentes mundos possíveis estes nomes denotam diferentes conjuntos. Assim, se na estrutura o mínimo/máximo de $\mathrm{N}$ se considera a interpretação intensional de $N$ (i.e., se se considera a denotação de $N$ em diferentes mundos possíveis), como descrito pela hipótese levantada acima, e dado que $N$ denota conjuntos diferentes em diferentes mundos possíveis, o significado da estrutura sintática leva a que tenha de se considerar a união dos conjuntos denotados por $N$ nos vários mundos possíveis. Ou seja, tem de se considerar uma pluralidade de conjuntos porque $N$ denota diferentes conjuntos em diferentes mundos possíveis.

Por último, há a considerar nomes massivos e nomes como poluição ou fumo.

Por um lado, estes nomes, como visto acima, podem ocorrer na construção o mínimo/máximo de $\mathrm{N}$, mas não na construção o mínimo/máximo $\mathrm{N}$ :

(31) a. Gastou o mínimo de cimento. / Poupa o máximo de cimento.

b. *Gastou o mínimo cimento. / *Poupa o máximo cimento!

Por outro lado, um nome massivo identifica a mesma substância em qualquer mundo possível, o mesmo sendo válido para nomes como poluição ou fumo. Assim, no que respeita à questão de a denotação do nome ser ou não a mesma em qualquer mundo possível, estes nomes são do mesmo tipo que nomes como ruído ou dano. No entanto, ao contrário destes nomes, que, como visto, podem ocorrer em ambas as construções sintáticas consideradas (o mínimo/máximo $\mathrm{N}$ e o mínimo/máximo de $\mathrm{N}$ ), os nomes massivos e nomes como polui- 
ção ou fumo podem ocorrer apenas na construção o mínimo/máximo de $\mathrm{N}$. Este facto não parece explicável pela hipótese em análise. Pelo contrário, esperar-se-ia que estes nomes (massivos ou do tipo poluição ou fumo) tenham o mesmo comportamento que os outros nomes que identificam a mesma entidade em qualquer mundo possível, contrariamente ao que se verifica.

A explicação que proponho para este facto é a seguinte: na interpretação da estrutura o mínimo N, sendo $N$ um nome massivo, está excluída a leitura em que a construção é equivalente a $o$ menor $\mathrm{N}$, que existe em casos como o mínimo obstáculo ou a mínima pedra, uma vez que $N$, sendo um nome massivo, identifica uma substância e não um conjunto de entidades discretas. Resta, então, a interpretação em que o mínimo $\mathrm{N}$ é equivalente a a menor quantidade de $\mathrm{N}$, que existe em casos como o mínimo dano ou o mínimo prazer. No entanto, esta interpretação também é problemática numa leitura extensional do nome porque não existe apenas uma quantidade da substância em causa que seja a quantidade mínima. Por exemplo, se uma gota de água é a quantidade mínima de água, não se pode dizer acerca de cada gota de água que é a quantidade mínima de água, já que existem outras quantidades de água (outras gotas de água) idênticas.

Veja-se agora que a estranheza da construção o mínimo $\mathrm{N}$, sendo $N$ um nome massivo, melhora com a adição de um operador modal, como o adjetivo possível ou uma frase relativa modalizada:

(32) a. *Gasta o mínimo cimento!

b. ?Gasta o mínimo cimento possível! / ?Usa o mínimo cimento que puderes!

Neste caso, o sintagma o mínimo cimento possível identifica a menor das quantidades que é possível usar e não a quantidade mínima, em absoluto, de cimento. Ou seja, a construção (32a) é excluída porque o sintagma o mínimo de $\mathrm{N}$ não terá referência: considerando a substância identificada por $\mathrm{N}$, não existe uma quantidade dessa substância que seja inferior a todas as outras quantidades da mesma substância. A construção (32b) é mais aceitável porque envolve a consideração de todas as quantidades possíveis da substância em causa (um saco de cimento, $100 \mathrm{~kg}$ de cimento, $10 \mathrm{~kg}$ de cimento, etc.) e identifica a mínima dessas quantidades. Por outras palavras, com nomes massivos, não faz sentido considerar a quantidade mínima da substância identificada pelo nome, apenas a quantidade mínima possível.

Assim, o contraste de aceitabilidade entre (32a) e (32b) mostra que a estrutura o mínimo $\mathrm{N}$ tem uma interpretação extensional, sendo necessário adicionar um operador que leve à consideração de outros mundos possíveis para a estrutura ser interpretável. Já no que respeita à construção o mínimo de $\mathrm{N}$, a presença de um operador modal, embora possível, não é necessária nem altera o significado da construção:

(33) a. Gasta o mínimo de cimento!

b. Gasta o mínimo de cimento possível!

Este facto mostra que o significado da construção o mínimo de $\mathrm{N}$ é intensional, envolve a consideração de diferentes mundos possíveis, pelo que a presença do adjetivo possível (ou outro operador modal análogo, como uma frase relativa modalizada) é redundante.

Por conseguinte, a análise das estruturas sintáticas em causa com nomes massivos contribui para a confirmação da hipótese enunciada neste trabalho, de que as construções o mínimo $\mathrm{N}$ e $o$ mínimo de $\mathrm{N}$ têm, respectivamente, interpretação extensional e intensional, embora à primeira vista pareça contrariar tal hipótese.

A ser assim, o processamento semântico da estrutura sintática $o$ \{mínimo/máximo $\}$ de $\mathrm{N}$, ao contrário do da estrutura $o$ \{mínimo/máximo $\} \mathrm{N}$, convoca a consideração de mundos possíveis alternativos mesmo sem que esta estrutura sintática ocorra, por exemplo, sob o escopo de um verbo intensional ou que integre algum operador modal explícito, como, e.g., o adjetivo possível. Tratar-se-á, portanto, um caso de uma âncora modal: 
«Modal domains are projected from modal anchors according to fixed recipes. Modal anchors are individuals, events, and situations that are independently made available in the course of a syntactic derivation.» (Hacquard (2006))

\section{Conclusão}

A análise semântica das estruturas o mínimo/máximo $\mathrm{N}$ e o mínimo/máximo de $\mathrm{N}$ permite concluir que:

(i) A estrutura o mínimo/máximo de $\mathrm{N}$ convoca a consideração de alternativas (de diferentes mundos possíveis), enquanto a estrutura o mínimo/máximo $\mathrm{N}$ tem interpretação extensional, sendo interpretada apenas relativamente ao mundo de avaliação (por defeito, o mundo real). A consideração de mundos alternativos nesta última estrutura exige a presença de outros elementos na construção, como um adjetivo modal (e.g. possível) ou uma frase relativa modalizada (e.g. que conseguires), ao contrário do que se verifica na estrutura o mínimo de $\mathrm{N}$, em que a presença de operadores modais deste tipo é opcional e não altera o significado da construção (o que mostra que, mesmo sem a presença destes operadores, o significado da construção é intensional).

(ii) A distribuição dos nomes que podem ocorrer em cada um dos dois tipos de construção decorre de (i) em conjugação com o facto de cada nome classificar as mesmas entidades em todos os mundos possíveis ou não.

\section{Referências}

Fauconnier, Gilles (1975) Pragmatic scales and logical structures. Linguistic Inquiry 6 (3), pp. 353-75.

Giannakidou, Anastasia (1997) Polarity sensitivity as (non)veridical dependency. Amesterdão: John Benjamins.

Hacquard, Valentine (2006) Aspects of modality. Dissertação de Doutoramento, MIT.

Haspelmath, Martin (1997) Indefinite Pronouns. Oxford: Clarendon Press.

Hoeksema, Jack (2000) Negative polarity items. In L. Horn e Y. Kato, (orgs.) Negation and Polarity: syntactic and semantic perspectives. Oxford: Oxford University Press, pp. 115-146.

Horn, Laurence R. (1972) On the Semantic Properties of Logical Operators in English. Dissertação de Doutoramento, IULC.

Israel, Michael (2001) Minimizers, maximizers and the rhetoric scalar reasoning. Journal of Semantics 18 (4), pp. 297-331.

Link, Godehard (1983) The Logical Analysis of Plurals and Mass Terms: A Lattice-Theoretical Approach. In G. Link Meaning and Interpretatton of Language, Berlim: de Gruyter.

Meulen, Alice ter (1980) Substances, Quantities and Individuals - a Study in the Formal Semantics of Mass Terms. Indiana: Indiana University Linguistics Club.

Peres, João A. (2013) Semântica do Sintagma Nominal. In Eduardo B. P. Raposo et al. (orgs.) Gramática do Português. Lisboa: Fundação Calouste Gulbenkian, pp. 735-815. 